\title{
Desain dan Implementasi Sistem Monitoring Sumber Daya Server Menggunakan Zabbix 4.0
}

\author{
(Design and Implementation of A Server Resource Monitoring \\ System Using Zabbix 4.0)
}

\author{
Sulasno Sulasno ${ }^{1}$, Rakhmat Saleh ${ }^{2}$ \\ ${ }^{1,2}$ Pusat Pendayagunaan Informatika dan Kawasan Strategis Nuklir (PPIKSN) \\ Badan Tenaga Nuklir Nasional (BATAN) Tangerang Selatan Banten
}

Kawasan Puspiptek Gedung 90 PPIKSN-BATAN Serpong Tangerang Selatan Banten

1 sulasnolbatan $\cdot$ go. id
2 rakhmats dbatan.go.id

\begin{abstract}
Abstrak - Penggunaan server pada suatu instansi pemerintah atau perusahaan swasta akan selalu bertambah seiring dengan meningkatnya penggunaan aplikasi. Masalah yang ada dengan penggunaan server yang berjumlah banyak dan belum dilengkapi dengan sistem monitoring server adalah sulitnya melakukan pemantauan penggunaan sumber daya server-server secara realtime, jika terjadi gangguan operasional seperti hard disk penuh dan kinerja CPU (Central Processing Unit) yang melebihi seharusnya, tidak cepat terpantau untuk segera ditangani. Penelitian ini bertujuan untuk membangun sistem monitoring sumber daya server secara realtime. Metode penelitian yang dilakukan meliputi pengumpulan data, desain sistem, instalasi dan konfigurasi, serta implementasi menggunakan Zabbix 4.0. Sebagai studi kasus berlokasi di Pusat Pendayagunaan Informatika dan Kawasan Strategis Nuklir (PPIKSN) Badan Tenaga Nuklir Nasional (BATAN). Hasil penelitian ini adalah sistem monitoring penggunaan sumber daya server yang meliputi kuota hard disk, utilitas CPU, penggunaan memori, besaran paket data ethernet, dan notifikasi email. Hasil dari penelitian ini telah digunakan oleh Administrator server. Para Administrator telah memberikan informasi akan manfaat sistem ini untuk kemudahan monitoring sumber daya server secara realtime, bekerja lebih efisien dan produktif, mengidentifikasi dan mengatasi masalah sebelum ada komplain, sehingga kualitas layanan semakin meningkat.
\end{abstract}

Kata-kata kunci: Monitoring Server, Sumber Daya Server, Zabbix.

Abstract - The use of servers in a government agency or private company will always grow as increases in application usage. The problem with using a large number of servers and not yet equipped with a server monitoring system is the difficulty of monitoring the use of server resources in real time, if there are operational interruptions, such as a full hard disk and CPU (Central Processing Unit) performance that exceeds it should, not quickly monitored for immediate handling. This research aims to build a realtime server resource monitoring system. Research methods carried out include data collection, system design, installation and configuration, and implementation using Zabbix 4.0. As a case study it is located at the Center for Information Utilization and the Nuclear Strategic Area (PPIKSN) of the National Nuclear Energy Agency (BATAN). The result of this research is the monitoring system of server resources usage which includes hard disk quota, CPU utility, memory usage, ethernet data packet size, and email notification. The result of this reseacrh have been used by server Administrators. Administrators have provided information on the benefits of this system to facilitate monitoring of server resources in realtime, work more efficient and productive, identify and resolve problems before there are complaints, so that the quality of service can be improved.

Keywords: Server Monitoring, Server Resources, Zabbix.

\section{PENDAHULUAN}

Ketergantungan penggunaan teknologi informasi (TI) untuk mendukung proses bisnis organisasi, baik instansi pemerintah atau perusahaan swasta sudah cukup tinggi. Ketergantungan pada TI diantaranya melalui penggunaan berbagai aplikasi sistem informasi yang berjalan di berbagai server. Sebagai contoh Pusat Pendayagunaan Informatika dan Kawasan Strategis Nuklir (PPIKSN) Badan Tenaga Nuklir Nasional (BATAN), sampai saat ini mengelola 58 server. Serverserver tersebut digunakan untuk menjalankan sistem informasi, baik sistem informasi yang merupakan aplikasi internal maupun aplikasi layanan publik untuk 
masyarakat luas. Berbagai aplikasi yang berjalan pada server-server akan menyimpan data setiap saat dengan pertumbuhan data yang cukup tinggi. Disamping itu pengguna dari internal maupun dari masyarakat umum dalam mengakses layanan publik membutuhkan layanan prima. Oleh sebab itu diperlukan server-server yang berkinerja handal sebagai tempat dieksekusinya aplikasi, supaya dapat bekerja secara efektif dan efisien.

Masalah pengelolaan server yang terdapat di PPIKSN-BATAN adalah belum terdapat sistem pemantau sumber daya server-server secara realtime dan terpusat, sehingga jika terdapat masalah pada operasional server seperti hard disk penuh, kinerja CPU (Central Processing Unit) yang melebihi seharusnya, dan paket data yang melewati ethernet sangat besar dari yang semestinya tidak cepat terpantau untuk segera ditangani. Selain permasalahan diatas secara umum perangkat lunak yang digunakan untuk operasional TIK seperti sistem operasi dan perangkat lunak untuk pengembangan aplikasi menggunakan software berbasis open source dan free. Lingkungan operasional TIK yang demikian memberikan banyak keuntungan, karena disamping penghematan anggaran, meningkatkan kreatifitas personil TIK, juga budget yang ada bisa digunakan untuk meningkatan kemampuan sumber daya manusia atau belanja peralatan TIK yang sangat diperlukan. Oleh karena itu solusi yang sesuai dari masalah yang dikemukakan tersebut adalah dengan membangun server monitoring yang memantau penggunaan sumber daya server-server secara realtime dan ditampilkan pada sebuah dashboard berbasis web menggunakan Zabbix yang bersifat open source dan free.

\section{A. Sumber Daya Sistem}

Sumber daya sistem komputer adalah komponen fisik atau virtual dari ketersediaan perangkat terbatas dalam sistem komputer. Setiap perangkat yang terhubung ke sistem komputer adalah sumber daya. Setiap komponen internal adalah sumber daya. Sumber daya sistem virtual mencakup file, koneksi jaringan, area memori, waktu $\mathrm{CPU}$, ruang hard disk, dan perangkat pendukung internal lainnya [1]. Ketersediaan sumber daya server sangat diperlukan untuk menjaga kinerja server supaya tetap handal [2] [3].

\section{B. Monitoring Sistem}

Sistem pemantauan dapat didefinisikan sebagai elemen yang diimplementasikan ke perangkat jaringan/server target. Kegiatan ini dilakukan secara berkala untuk memeriksa ketersediaan dan status kinerja setiap node serta tautan. Dalam hal ada masalah atau beberapa elemen tidak tersedia, sistem pemantau secara otomatis memberitahu Administrator yang bertanggung jawab. Pada beberapa kasus dimungkinkan untuk secara aktif mengelola jaringan/server menggunakan sistem pemantauan. Kita juga bisa mendefinisikan cara-cara efektif dan efisien yang akan digunakan untuk mendeteksi kasus/permasalahan yang ada [4] [5].

\section{Zabbix}

Salah satu perangkat lunak yang banyak digunakan untuk implementasi sistem monitoring sumber daya server atau perangkat jaringan adalah Zabbix [6]. Tentu saja banyak kriteria yang harus dipenuhi dalam memilih perangkat lunak monitoring, tetapi kelebihan perangkat lunak ini adalah open source dan free, antarmuka berbasis grafis, dan menggunakan database SQL (Structured Query Language) sebagai pengelola data [7] [8]. Disamping itu Zabbix merupakan perangkat lunak berbasis multiplatform yang digunakan untuk memonitor ketersediaan sumber daya server maupun infrastruktur perangkat jaringan dengan sistem pemantauan yang terdistribusi. Zabbix dapat menghasilkan laporan statistik berbasis grafis, screen monitoring, dan notifikasi melalui email, apabila ada perangkat yang mengalami masalah.

Zabbix memiliki properti yang tidak kalah lengkapnya dengan perangkat lunak yang berbayar seperti Avaya VPFM, Cruz, Inter Mapper, IsyVmon dan lainnya. Sementara itu perangkat berbayar yang memiliki kriteria yang sama dengan Zabbix diantaranya HPE Openview, Solarwind, dan Sevone [9]. Oleh sebab itu pemilihan Zabbix untuk digunakan dalam sistem monitoring adalah suatu keuntungan, karena disamping free dan open source, tetapi memiliki kekayaan properti seperti produk berbayar yang ada di pasaran. Zabbix harus diinstalasi dan dikonfigurasi. Dalam penelitian ini terdapat dua perangkat utama untuk arsitektur Zabbix yang digunakan, yaitu Zabbix-server dan Zabbix-agent. Zabbix-server adalah proses utama dari perangkat lunak Zabbix yang dipasang pada server utama sebagai pemantau. Zabbix-agent adalah UNIX daemon yang berjalan pada host (server) yang sedang dipantau. Agent ini memberikan informasi kondisi penggunaan sumber daya host yang dipantau dan mengirimkan informasiinformasi tersebut ke Zabbix-server. Protokol untuk berkomunikasi dalam sistem Zabbix sangat sederhana diantaranya adalah TCP/IP (Transmission Control Protocol/Internet Protocol) atau SNMP (Simple Network Management Protocol) yang secara umum sudah dipakai pada perangkat jaringan maupun server. Kelebihan lainnya dari Zabbix adalah Administrator dapat memonitor sumber daya melalui dashboard berbasis grafis dan mudah untuk dikonfigurasi [10]. 
Penelitan ini bertujuan untuk membangun sistem monitoring penggunaan sumber daya server. Sistem didesain dan diinstalasi maupun konfigurasi untuk melakukan pemantauan penggunaan sumber daya server-server secara realtime. Hasil monitoring ditampilkan dalam sebuah dashboard berbasis web yang dapat diakses secara online melalui aplikasi browser menggunakan alamat IP (Internet Protocol) lokal. Jika terdapat masalah pada penggunaan sumber daya, maka sistem monitoring akan memberikan notifikasi melalui email Administrator. Sumber daya server yang dipantau meliputi kuota hard disk, utilitas CPU, penggunaan memori, dan besaran lalu lintas paket data ethernet server.

\section{METODE}

Metode penelitian yang digunakan pada kegiatan desain dan implementasi sistem monitoring sumber daya server menggunakan Zabbix 4.0 meliputi pengumpulan data, desain sistem, instalasi dan konfigurasi, serta implementasi. Tahapan metode penelitian yang meliputi 4 langkah tersebut dilaksanakan untuk menghasilkan sistem monitoring sumber daya server sesuai dengan kondisi topologi jaringan serta sistem operasi server yang digunakan.

\section{A. Pengumpulan Data}

Pengumpulan data dilakukan dengan datang langsung ke bagian yang mengelola pusat data dan jaringan komputer di PPIKSN-BATAN. Termasuk dalam kegiatan ini diantaranya adalah mewancarai secara langsung beberapa Administrator server maupun jaringan untuk mendapatkan data-data server, topologi jaringan, dan firewall yang digunakan.

\section{B. Desain Sistem}

Pada tahap ini dilakukan desain arsitektur sistem monitoring sumber daya server menggunakan Zabbix 4.0. Desain arsitektur sistem monitoring diperlihatkan pada Gambar 1. Secara umum arsitektur terdiri dari tiga bagian yaitu Server Monitoring (SERMON), Server Agent (SERA), dan Perangkat Administrator untuk Monitoring (PAM) [10]. SERMON adalah server utama untuk monitoring sumber daya server, yang memiliki tiga komponen utama yaitu Zabbix-server, Zabbixdatabase, dan Zabbix-web-frontend. Zabbix-server adalah perangkat inti dari SERMON yang memantau SERA.

SERMON memantau seluruh server-server yang dimonitor berdasarkan laporan dari SERA. Zabbixdatabase merupakan pangkalan data dimana informasi hasil monitoring disimpan oleh Zabbix-server, serta diakses melalui Zabbix-web-frontend pada saat dibutuhkan. Zabbix-web-frontend adalah antarmuka berbasis web yang bisa diakses melalui jaringan menggunakan aplikasi browser PAM saat diperlukan. SERA adalah perangkat server yang dipantau keadaan sumber dayanya. Untuk memantau SERA Zabbix-agent harus sudah diinstalasi dan dikonfigurasi di dalamnya. Selanjutnya PAM adalah perangkat yang digunakan oleh Administrator server untuk memantau keadaan sumber daya. Administrator juga dapat mengkonfigurasi trigger dan waktu respon pemantauan melalui SERMON untuk dikirimkan ke SERA, sehingga SERA akan megirimkan informasi sesuai dengan konfigurasi yang diinginkan.

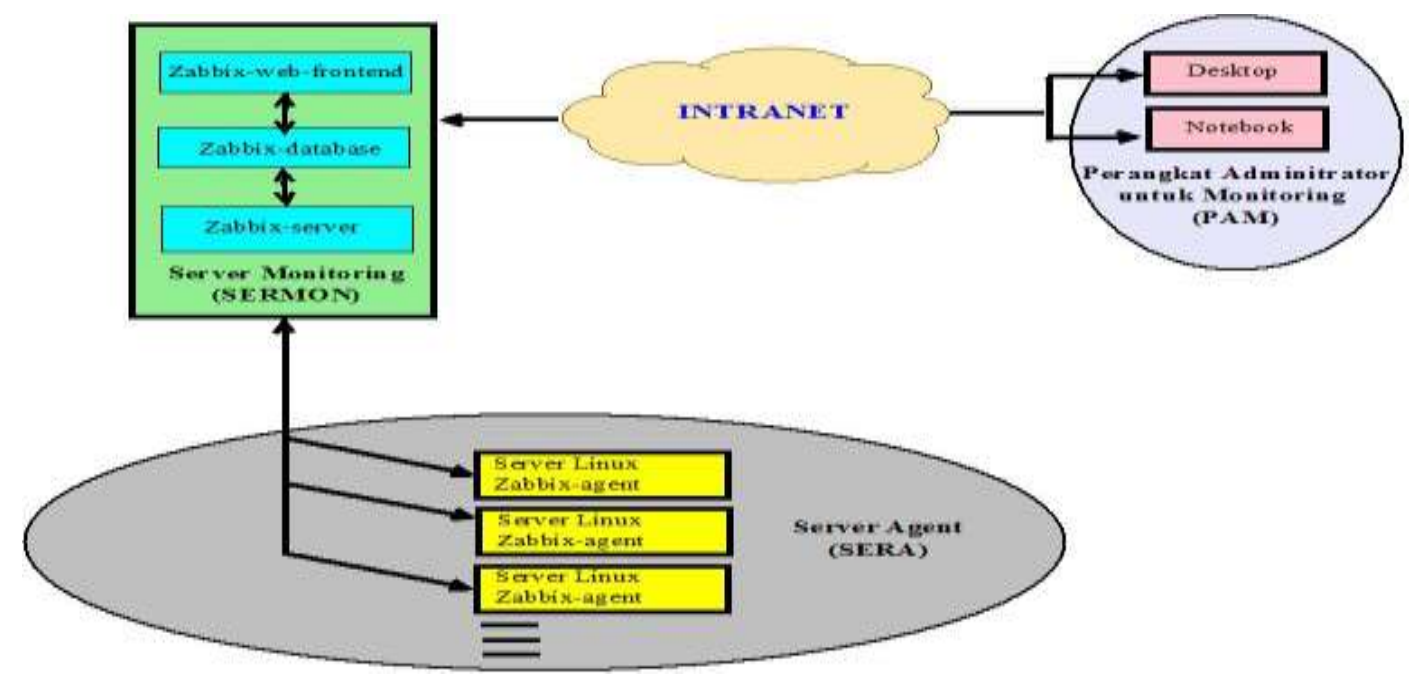

Gambar 1. Desain sistem monitoring 


\section{Instalasi dan Konfigurasi}

Kegiatan instalasi dan konfigurasi sistem monitoring menggunakan Zabbix-server 4.0 dan Zabbix-agent 4.0 dengan sistem operasi Centos 7.7, melalui beberapa tahapan yang disampaikan pada flowchart di Gambar 2. Dari flowchart pada Gambar 2 dapat dijelaskan secara detail tahapan pelaksanaan yang dilakukan.

\section{1) Mempelajari Topologi Jaringan dan Menentukan} Posisi Server Monitoring. Pada tahap ini dilakukan kegiatan mempelajari topologi jaringan yang digunakan. Kegiatan mempelajari topologi jaringan penting dilakukan untuk menentukan posisi/letak server yang akan digunakan sebagai server monitoring (SERMON). Karena dalam menentukan posisi SERMON harus mempertimbangkan komunikasi antara SERMON dengan SERA.

2) Instalasi dan Konfigurasi Sistem Operasi Centos 7.7. Kegiatan pertama pada tahap ini adalah menyiapkan perangkat server yang akan dijadikan sebagai SERMON. Kemudian dilakukan instalasi sistem operasi Centos 7.7. Setelah selesai melakukan instalasi dilanjutkan dengan kegiatan konfigurasi sistem.

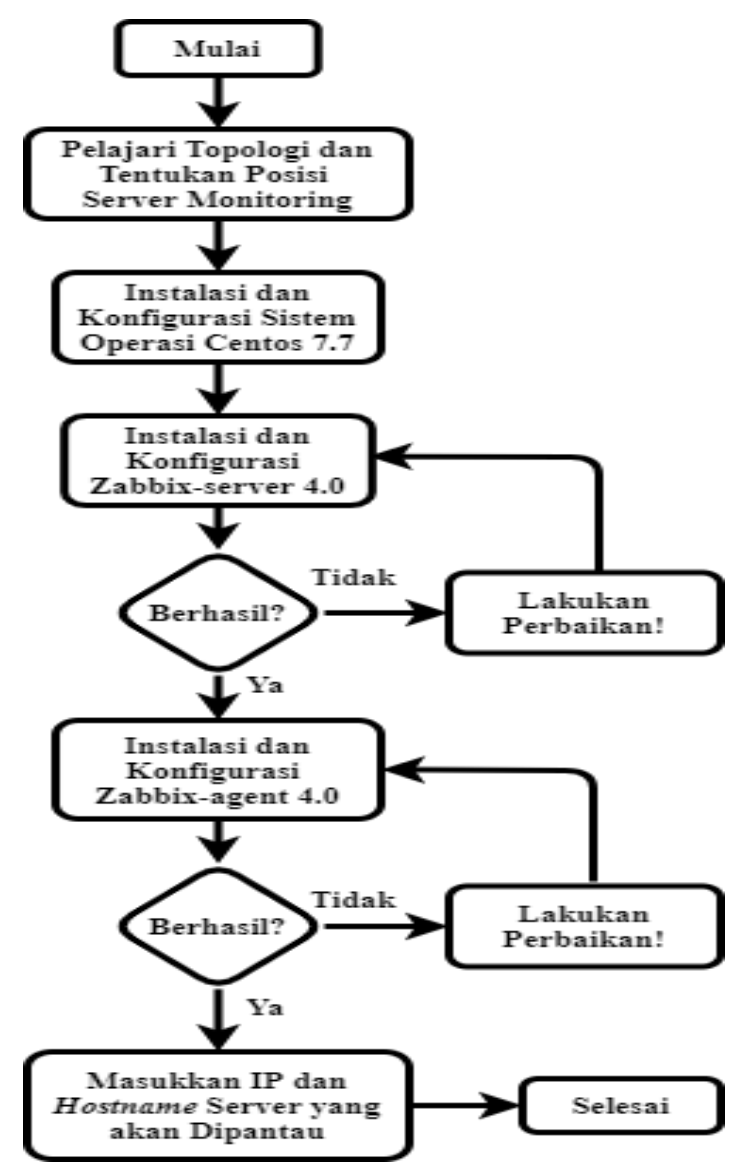

Gambar 2. Tahapan instalasi dan konfigurasi
3) Instalasi dan Konfigurasi Zabbix-server 4.0. Instalasi Zabbix-server 4.0 dilakukan setelah proses instalasi dan konfigurasi sistem operasi Centos $7.7 \mathrm{di}$ SERMON selesai dilaksanakan. Dalam proses instalasi Zabbix-server 4.0 Administrator menggunakan perintahperintah yang digunakan untuk proses instalasi. Setelah kegiatan instalasi selesai dilanjutkan dengan konfigurasi perangkat lunak ini yang meliputi konfigurasi Zabbixserver, konfigurasi Zabbix-database, dan konfigurasi Zabbix-web-frotend. Disamping itu dilakukan juga konfigurasi port firewall internal di SERMON tersebut.

4) Instalasi dan Konfigurasi Zabbix-agent 4.0. Kegiatan penting selanjutnya adalah melakukan instalasi Zabbix-agent 4.0 di SERA. Setelah selesai melakukan kegiatan instalasi dilanjutkan dengan konfigurasi yang meliputi konfigurasi Zabbix-agent 4.0 dan konfigurasi port firewall internal di server tersebut.

5) Memasukkan Data Nomor IP dan Hostname Server yang Dipantau. Pada tahap ini dimasukkan IP dan hostname SERA, namun harus melalui menu dashboard di SERMON.Termasuk dalam kegiatan ini adalah membuka port komunikasi yang berada di firewall server maupun firewall jaringan serta mengkonfigurasi email alert [7] [11].

\section{Implementasi}

Pada tahap implementasi Administrator melakukan monitoring penggunaan sumber daya SERA yang dipantau melalui sebuah dashboard berbasis web. Sedangkan untuk pengecekan notifikasi email, dilakukan dengan cara membuka email Administrator yang digunakan untuk melihat apakah ada notifikasi email atau sumber daya server yang bermasalah. Sumber daya yang dipantau meliputi penggunaan hard disk, utilitas CPU, penggunaan memori, dan besaran paket data yang lewat melalui ethernet [12] [13].

\section{HASIL DAN PEMBAHASAN}

\section{A. Instalasi dan Konfigurasi}

Topologi jaringan komputer yang digunakan untuk meletakkan server-server di pusat data PPIKSN dibagi dalam tiga zona DMZ (Demilitarized Zone) yaitu DMZ1, DMZ2, dan DMZ3. Jumlah server-server pada setiap zona diperlihatkan pada Tabel I. Kegiatan mempelajari topologi dan menentukan posisi SERMON di jaringan penting dilakukan karena harus mempertimbangkan komunikasi antara SERMON dengan SERA [7] [14]. Pada penelitian ini SERMON diletakkan pada topologi jaringan di DMZ1 dengan pertimbangan beban/jumlah server di zona tersebut lebih sedikit, dibandingkan dengan jumlah server-server yang diletakkan pada zona 
DMZ2 dan DMZ3. Server-server yang terletak di DMZ1 sebagian besar adalah server-server untuk menjalankan aplikasi sistem informasi berbasis web, baik itu sistem informasi untuk keperluan internal maupun sistem informasi untuk keperluan publik. Tentu saja serverserver tersebut tidak sesibuk server email atau server proxy yang terdapat di zona selain DMZ1. Perlu diinformasikan bahwa dengan jumlah server yang lebih sedikit dalam kondisi normal, maka beban jaringan (kesibukan paket data yang lewat dalam kondisi normal) juga semakin sedikit, jika dibandingkan dengan beban jaringan di zona DMZ2 dan DMZ3.

Kegiatan selanjutnya adalah menyiapkan mesin/server yang akan digunakan sebagai SERMON. Dalam penelitian ini digunakan server virtual dari sistem Hyper-Converged Infrastructure (HCI) dengan spesifikasi virtual machine (VM) seperti yang ditunjukkan pada Tabel II [15]. Setelah SERMON tersedia maka kegiatan berikutnya melakukan instalasi sistem operasi Centos 7.7. Sesudah kegiatan instalasi sistem operasi selesai, kemudian dilakukan konfigurasi pasca instalasi yang meliputi konfigurasi nama pengguna dan jaringan (hostname, IP, DNS (Domain Name System)).

TABEL I

DAFTAR JUMLAH SERVER SETIAP ZONA

\begin{tabular}{ccc}
\hline No & Zona & Jumlah Server \\
\hline 1 & DMZ1 & 10 \\
2 & DMZ2 & 33 \\
3 & DMZ3 & 15 \\
\hline
\end{tabular}

TABEL II

SPESIFIKASI VM SERMON

\begin{tabular}{ccc}
\hline No & Nama Perangkat & Jumlah \\
\hline 1 & Prosesor & 4 Core \\
2 & Memori & $16 \mathrm{~Gb}$ \\
3 & Hard disk & $400 \mathrm{~GB}$ \\
4 & Ethernet Card & $100 \mathrm{Mbps}$ \\
\hline
\end{tabular}

Aktivitas berikutnya melakukan instalasi Zabbixserver 4.0 di SERMON. Dalam proses instalasi Zabbixserver 4.0 Administrator menggunakan perintahperintah yang digunakan untuk instalasi. Sesudah kegiatan instalasi selesai, dilanjutkan dengan konfigurasi perangkat lunak tersebut, yang meliputi konfigurasi Zabbix-server 4.0, konfigurasi Zabbix-database, dan konfigurasi Zabbix-web-frotend. Disamping itu dilakukan juga konfigurasi port firewall internal untuk SERMON [11]. Sesudah kegiatan instalasi Zabbixserver 4.0 di SERMON selesai, dilanjutkan dengan kegiatan instalasi dan konfigurasi Zabbix-agent 4.0 di SERA yang akan dipantau. Termasuk dalam kegiatan ini adalah melakukan konfigurasi port firewall internal di SERA yang akan dimonitor.

\section{B. Implementasi Sistem Monitoring}

SERMON dan SERA telah selesai dilakukan instalasi dan konfigurasi. Hasil yang diperoleh adalah sistem monitoring sumber daya server yang dapat diakses melalui browser PAM dengan alamat https://10.1.128.13/zabbix. Apabila melakukan akses melalui browser ke alamat SERMON tersebut, maka tampilan pertama yang muncul adalah halaman login. Login pertama yang perlu dilakukan menggunakan akun: Admin dan password yang sama seperti yang dimasukan pada proses instalasi dan konfigurasi Zabbix-database. Setelah berhasil login Administrator dapat melakukan penataan tampilan dashboard dari menu yang ada, termasuk melakukan pembuatan akun pengguna dan password baru serta memasukan SERA yang akan dipantau. Pada kegiatan ini telah diuji coba memasukan SERA seperti tampil pada Gambar 3 yang diambil dari antarmuka SERMON. Dari tampilan antarmuka SERMON tersebut dapat diinformasikan bahwa telah dilakukan input SERA sebanyak 28 server. Nama-nama SERA berikut dengan nomor urutnya tampil di sebelah kiri. Sedangkan di sebelah kanan dari nama SERA adalah properti dari antarmuka tersebut yang meliputi Application, Items, Triggers, Graph, dan Discovery berikut dengan nilai parameternya. 


\begin{tabular}{|c|c|c|c|c|c|}
\hline 1.DIGILIB-V & Application 10 & Items 67 & Triggers 25 & Graph 14 & $\operatorname{\pi ry} 2$ \\
\hline 2.EKMR-PTKMR & Application 10 & Items 59 & Triggers 21 & Graph 13 & Discoverry 2 \\
\hline 3.MIRROR-BDG & Application 10 & Items 61 & Triggers 21 & Graph 14 & Discoverny 2 \\
\hline 4.PDK PASARJUMAT & Application 10 & Items 47 & Triggers 17 & Graph 10 & erry 2 \\
\hline 5.REPO-SIMN & Application 10 & Items 52 & Triggers 19 & Graph 11 & Discoverry 2 \\
\hline 6.SERPONG27 & Application 10 & Items 76 & Triggers 27 & Graph 17 & Discoverry 2 \\
\hline 7.SILAT & ation 10 & Items 56 & Triggers 23 & h 10 & erry 2 \\
\hline 8.SIMWA & Appl & Items 61 & Triggers 21 & & erry 2 \\
\hline 9.SII & 110 & 834 & Triggers 15 & 10 & verry 2 \\
\hline 10.5 & 10 & s 56 & rs 23 & 16 & $\operatorname{rry} 2$ \\
\hline 11. & n 10 & s. 71 & rs 25 & 115 & $\operatorname{xyy} 2$ \\
\hline 12.9 & on 10 & 561 & ers 21 & h 15 & ry 2 \\
\hline 13.DEV-PTBBN & on 10 & Items 66 & Triggers 23 & h 11 & erry 2 \\
\hline 14.PRTAL- & on 10 & Items 51 & Triggers 21 & h 10 & erry 2 \\
\hline 15.LMS-PD & on 10 & Items 50 & Triggers 19 & 11 & erry 2 \\
\hline 16.1 & n 10 & s 55 & Triggers 21 & 112 & Dis \\
\hline 17. & Ap & & Triggers 23 & & $\operatorname{rry} 2$ \\
\hline 18.1 & & & 23 & 10 & $\operatorname{rry} 2$ \\
\hline 19. & $\mathrm{Ap}$ & 51 & 21 & & erry 2 \\
\hline $20 . \mathrm{F}$ & in 11 & as 54 & 824 & 14 & Di \\
\hline 21.SIPRANUK-V & on 11 & Items 54 & Triggers 24 & Graph 13 & erry 2 \\
\hline 22.BATANPRESS-V & on 11 & Items 54 & Triggers 24 & Graph 15 & verry 2 \\
\hline 23.SIAPP-V & cation 11 & Items 54 & Triggers 24 & Graph 14 & Discoverry 2 \\
\hline 24.DEV-SIMN-2018 & Application 11 & Items 60 & Triggers 24 & Graph 11 & Discoverry 2 \\
\hline 25.SILABA-V & Application 10 & Items 51 & Triggers 21 & Graph 14 & Discoverry 2 \\
\hline 26.SISKA-V & Application 10 & Items 51 & Triggers 21 & Graph 10 & Discoverry 2 \\
\hline 27.DEV-SIMN- 2020 & Application 10 & Items 66 & Triggers 21 & Graph 14 & Discoverry 2 \\
\hline 28.BACKUP-M & Application 10 & Items 67 & Triggers 24 & Graph 11 & Discoverry 2 \\
\hline
\end{tabular}

\section{Gambar 3. Daftar SERA}

Selanjutnya disampaikan hasil monitoring SERMON terhadap SERA. Hasil monitoring meliputi informasi penggunaan sumber daya hard disk, utilitas CPU, penggunaan memori, dan besaran lalu lintas paket data ethernet baik paket data yang masuk ke sistem (incoming), maupun paket data yang keluar dari sistem (outgoing) [1] [16].Semua informasi hasil monitoring diambil dari dashboard berbasis web SERMON, yang diakses melalui browser PAM. Disamping itu informasi notifikasi email didapatkan dari hasil pengecekan email Administrator. Karena alasan ukuran gambar yang terlalu kecil jika rentang waktu yang digunakan terlalu panjang dalam pengamatan penggunaan sumber daya, maka pada gambar-gambar hasil monitoring yang ditampilkan menggunakan rentang waktu pendek dan diambil dalam beberapa pemantauan dengan waktu acak.

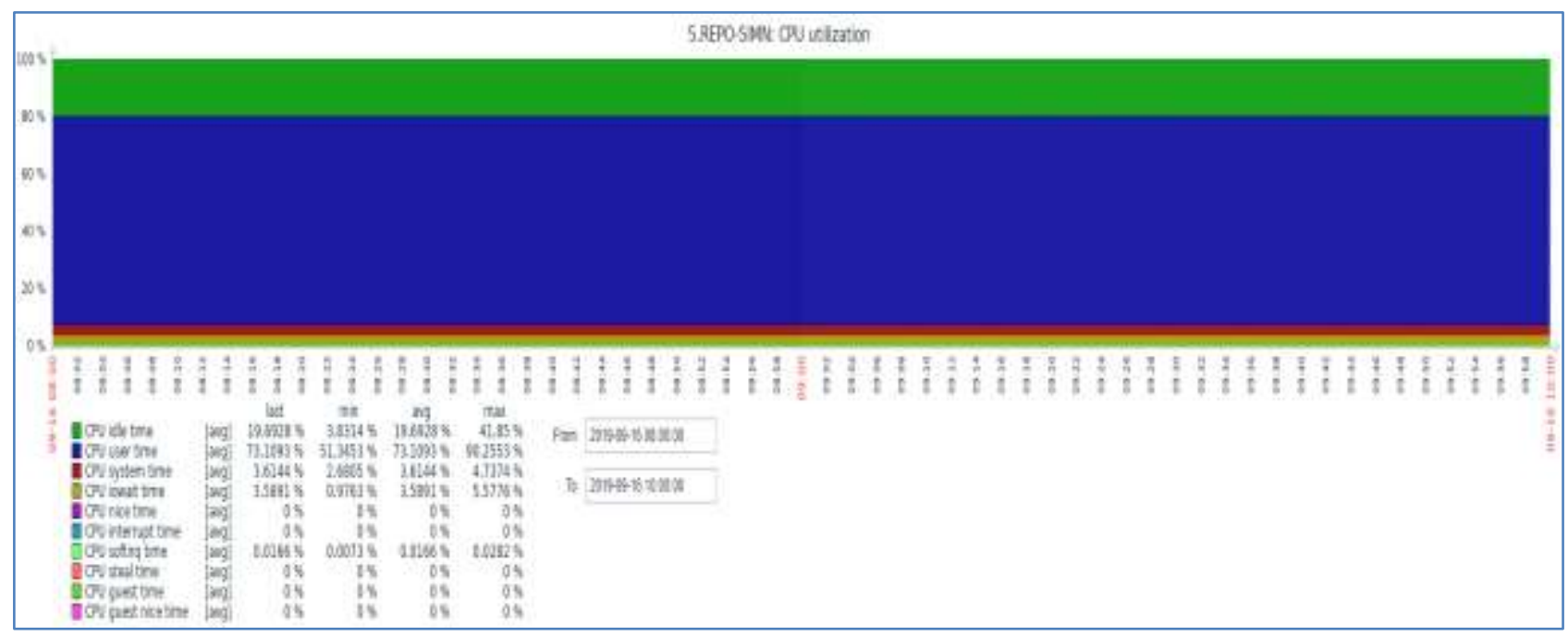

Gambar 4. Grafik utilitas CPU REPO-SIMN 
Gambar 4 menampilkan salah satu hasil monitoring utilitas CPU SERA yaitu REPO-SIMN yang dilakukan pada tanggal 16 September 2019 pukul 08:00-10:00 WIB (Waktu Indonesia Barat). Angka 5 di depan nama server pada gambar tersebut, menunjukkan urutan server yang dipasang pada dashboard SERMON. Dari Gambar 4 dapat dikemukakan bahwa utilitas kinerja CPU REPOSIMN rata-rata sebesar $80,31 \%$, karena idle time (waktu nganggur) rata-rata sebesar $19,69 \%$, yang ditunjukkan dengan gambar berwarna hijau. Utilitas CPU yang digunakan untuk aplikasi pengguna (user time) rata-rata sebesar $73,11 \%$, yang ditunjukkan dengan gambar berwarna biru. Sedangkan untuk sistem operasi (system time) rata-rata 3,61\%, yang ditunjukkan dengan gambar berwarna merah.

Selanjutnya pada Gambar 5 ditampilkan hasil pemantauan salah satu hard disk di SERA SILAT, yaitu hard disk yang kedua yang dalam sistem tersebut dikenali sebagai /home2. Perlu diinformasikan bahwa server SILAT memiliki 2 buah hard disk yaitu hard disk yang pertama digunakan untuk sistem operasi, dan hard disk kedua digunakan untuk menempatkan data-data aplikasi yang dijalankan. Pada hasil monitoring ini ditampilkan informasi ketersediaan ruangan hard disk yang kedua dengan alasan karena hard disk yang kedua memiliki pertumbuhan penambahan data yang lebih cepat dibandingkan dengan hard disk pertama, karena terdapat banyak aplikasi-aplikasi di dalamnya. Dari Gambar 5 dapat diinformasikan keadaan kuota partisi hard disk /home2 SERA SILAT yang diambil pada tanggal 21 Oktober 2019 pukul 10:00-12:00 WIB. Sisa kuota partisi /home2 adalah 707,45 GB $(77,16 \%)$ dari 916,89 GB.

Berikutnya pada Gambar 6 disampaikan hasil pemantauan penggunaan memori SERA SITP-V yang dilakukan pada tanggal 11 Desember 2019 pukul 10:00 12:00 WIB. Memori yang tersedia (tidak terpakai) ratarata 2,91 GB dari total memori sistem yang ada di server tersebut yaitu 4 GB. Memori yang tidak terpakai (available memory) ditunjukkan dengan gambar berwarna hijau.

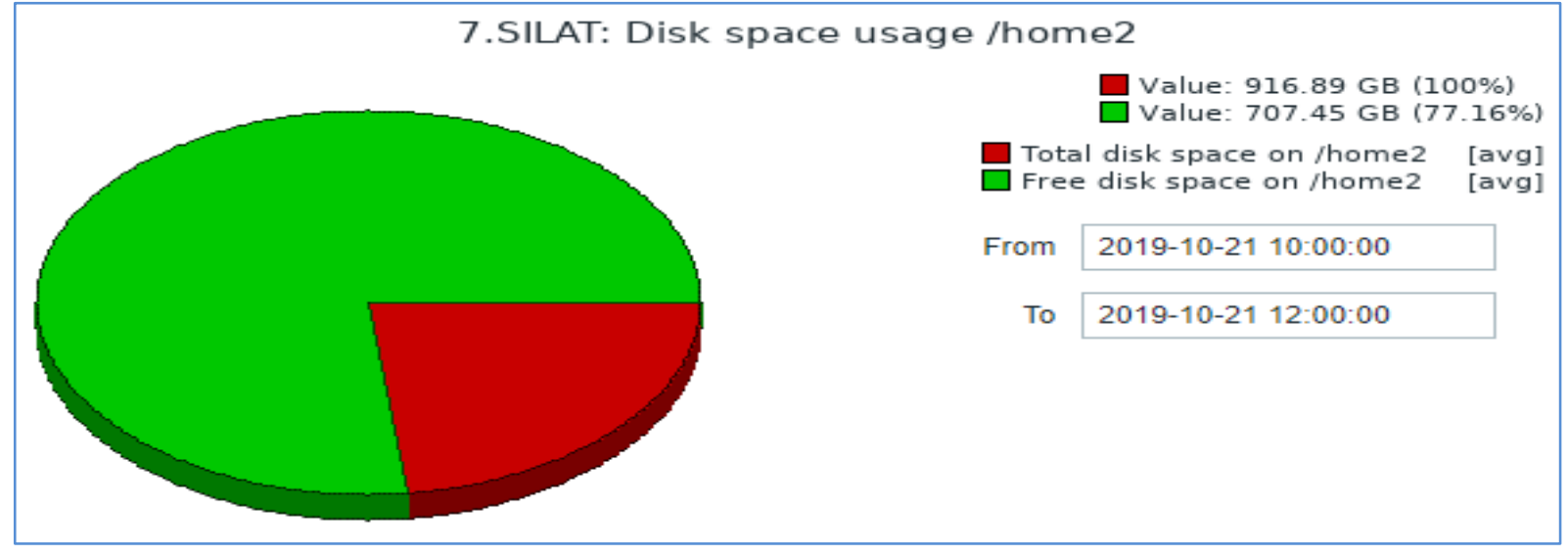

Gambar 5. Hasil pemantauan hard disk untuk partisi /home2 SILAT

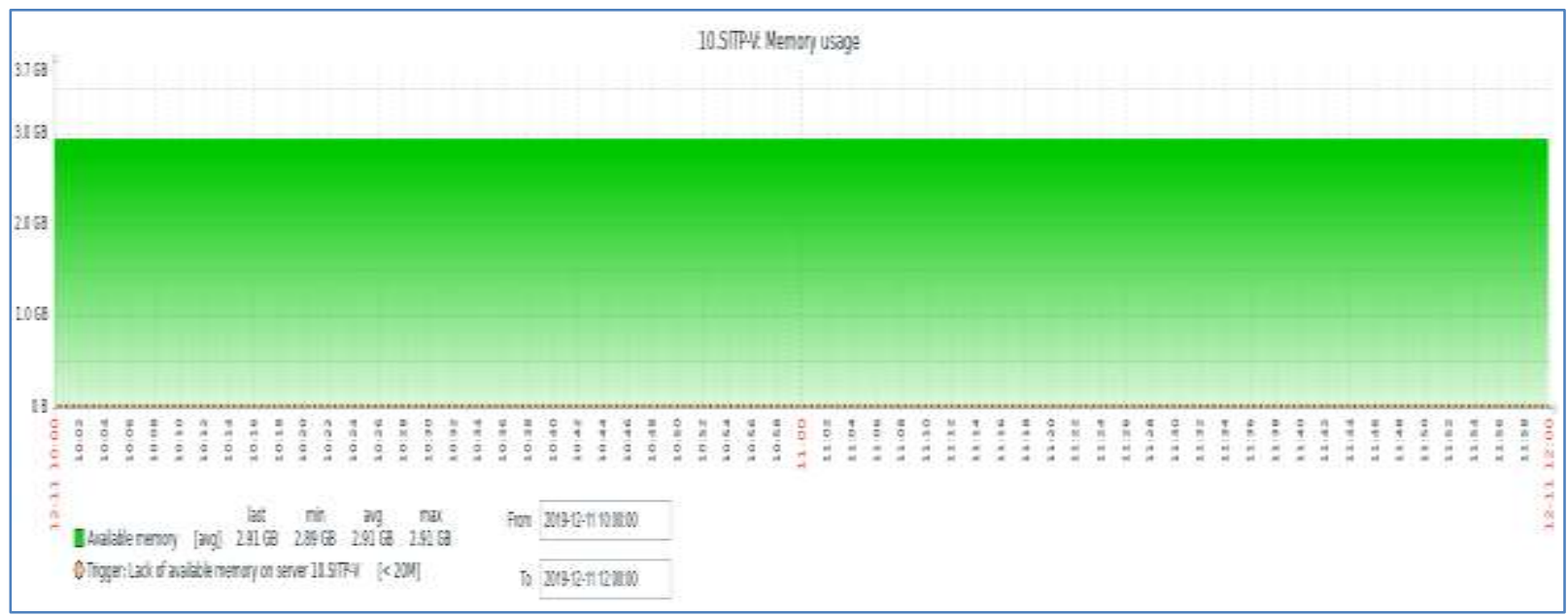

Gambar 6. Hasil pemantauan konsumsi memori SITP-V 
Gambar 7 menyampaikan hasil monitoring paket data yang lewat melalui ethernet SERA CLOUD-MITRA pada tanggal 24 Desember 2019 pukul 13:30 - 15:30 WIB. Warna hijau menunjukkan ukuran jumlah paket data yang masuk ke server CLOUD-MITRA. Sedangkan warna biru menunjukkan ukuran jumlah paket data yang keluar dari server tersebut. Lalu lintas data yang keluar dari sistem menurun mulai pukul 14:00 - 15:00 WIB, namun demikian rata-rata lalu lintas data berada pada kisaran 43,54 Kbps. Sementara itu paket data yang masuk ke sistem relatif stabil dengan rata-rata sekitar 33,14 Kbps. Secara umum lalu lintas paket data yang masuk ke server tersebut maupun yang keluar dari server menunjukkan keadaan normal, karena tidak ada lonjakan paket data yang tinggi misalnya sampai mencapai 100 Mbps atau diatasnya dan berlangsung dalam waktu yang lama sehingga dapat mengganggu lalu lintas data di jaringan lokal dimana server tersebut berada.
Gambar 8 menampilkan salah satu contoh screenshoot isi notifikasi email dari SERMON yaitu sermon@batan.go.id ke salah satu email Administrator sistem monitoring, yaitu sulasno@batan.go.id. Isi notifikasi menginformasikan bahwa SERMON telah selesai melakukan analisis masalah berdasarkan laporan dari SERA MIRROR-BDG yang mengindikasikan pada tanggal 05 Desember 2019 pukul 02:14 WIB kuota hard disk dengan partisi /home di SERA MIRROR-BDG tersisa lebih kecil $20 \%$ dari total volume partisi har disk yang ada di server tersebut. Tingkat keparahan dari masalah tersebut (severity) adalah warning (peringatan). Berdasarkan notifikasi email tersebut maka Administrator server dapat melakukan tindakantindakan manual yang diperlukan seperti memindahkan berkas data dari partisi /home di server tersebut ke server backup atau menghapus berkas data-data yang tidak berguna atau tindakan solusi lainnya.

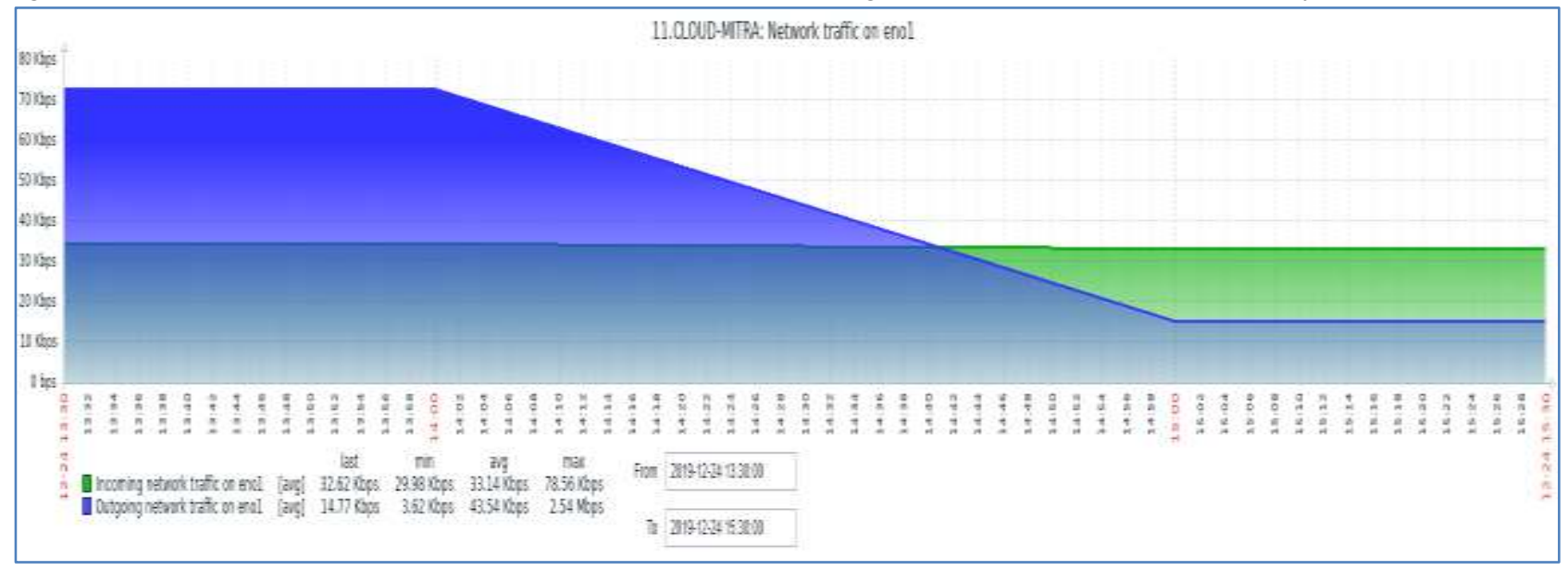

Gambar 7. Grafik ethernet CLOUD-MITRA

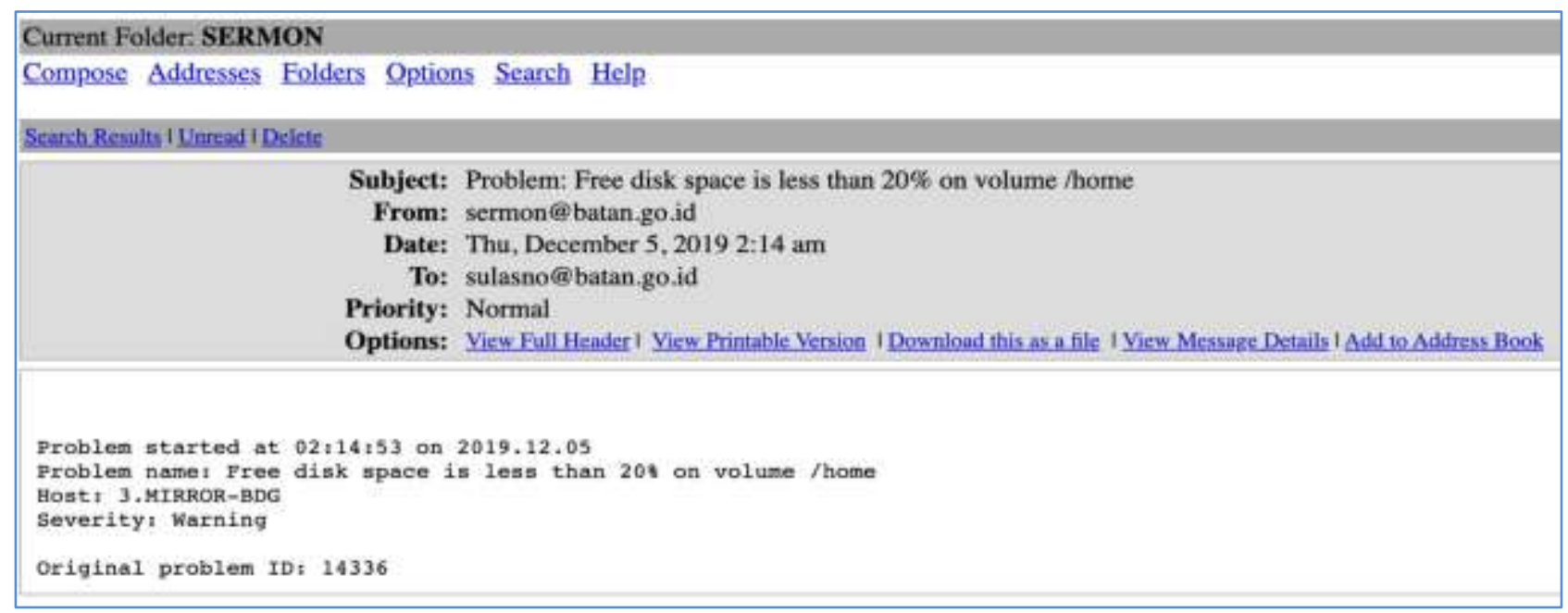

Gambar 8. Notifikasi email untuk masalah sisa volume hard disk MIRROR-BDG 
Berdasarkan data keadaan sumber daya server-server yang ditampilkan pada Gambar 4 sampai dengan Gambar 8 yang mewakili informasi hasil monitoring SERMON terhadap SERA untuk beberapa server, dapat dikemukakan bahwa sistem monitoring sumber daya server dapat berjalan dengan baik, sesuai dengan konfigurasi sistem yang telah dilakukan. Hasil monitoring yang berisi informasi penggunaan sumber daya server secara realtime ditampilkan pada sebuah dashboard berbasis web, yang dapat diakses secara online menggunakan aplikasi browser PAM. Sistem monitoring berjalan dengan baik jika informasi yang ditampilkan sesuai dengan hasil konfigurasi sistem yang diinginkan untuk monitoring sumber daya server-server yang digunakan [12] [17]. Selanjutnya berkaitan dengan manfaat dari sistem monitoring ini, telah dilakukan wawancara secara langsung dengan Administrator pengelola server yang sudah menggunakan sistem ini. Dari hasil wawancara didapatkan informasi bahwa sistem monitoring yang telah dikembangkan ini memberikan kemudahan pemantauan penggunaan sumber daya server-server secara realtime. Disamping itu Administrator menambahkan informasi bahwa dengan bantuan sistem ini mereka bekerja lebih efisien dan produktif, mengidentifikasi dan mengatasi masalah sebelum ada komplain, sehingga kualitas layanan semakin meningkat.

\section{PENUTUP}

Telah berhasil dilakukan kegiatan desain dan implementasi sistem monitoring sumber daya server menggunakan Zabbix 4.0. Hasil yang didapat adalah sistem monitoring penggunaan sumber daya serverserver yang ditampilkan pada sebuah dashboard secara realtime dan dapat diakses melalui intranet oleh Administrator. Informasi yang ditampilkan meliputi besaran kuota partisi hard disk, utilitas CPU, penggunaan memori, lalu lintas paket data yang lewat melalui ethernet, dan alert server yang bermasalah melalui email. Informasi-informasi yang ditampilkan memudahkan Administrator server untuk melakukan evaluasi penggunaan sumber daya dan merancang pengembangan kapasitas server atau penambahan sumber daya yang diperlukan. Pada kegiatan yang telah dilakukan hanya memonitor server-server berjumlah 28 unit dengan sistem operasi Centos, untuk itu perlu dilakukan penambahan jumlah server yang dimonitor dengan sistem operasi yang berbeda. Perlu dilakukan uji coba monitoring perangkat jaringan dan perangkat pusat data seperti router, switched manageble, Access Point, UPS (Uninterruptible power supply), NAS (Network Attached Storage) dan SAN (Storage Area Network) di jaringan komputer dan pusat data PPIKSN-BATAN menggunakan protocol SNMP sehingga keberadaan sistem ini menjadi lebih berdaya guna.

\section{DAFTAR PUSTAKA}

[1] K. B. Sandeep, M. Raghavendra, and K. J. Shetty, "Performance analyzer: An approach for performance analysis of enterprise servers," 2016 IEEE Int. Conf. Recent Trends Electron. Inf. Commun. Technol. RTEICT 2016 - Proc., pp. 480-484, 2017, doi: 10.1109/RTEICT.2016.7807867.

[2] P. Garraghan, P. Townend, and J. Xu, "An analysis of the server characteristics and resource utilization in Google cloud," Proc. IEEE Int. Conf. Cloud Eng. IC2E 2013, pp. 124-131, 2013, doi: 10.1109/IC2E.2013.40.

[3] A. Datt, A. Goel, and S. C. Gupta, "Analysis of Infrastructure Monitoring Requirements for OpenStack Nova," Procedia Comput. Sci., vol. 54, pp. 127-136, 2015, doi: 10.1016/j.procs.2015.06.015.

[4] A. Iqbal, C. Pattinson, and A. L. Kor, "Performance monitoring of Virtual Machines (VMs) of type i and II hypervisors with SNMPv3," 2015 World Congr. Sustain. Technol. WCST 2015, pp. 98-99, 2016, doi: 10.1109/WCST.2015.7415127.

[5] Z. Jiang, "A Linux Server Operating System's Performance Comparison Using Lmbench," 2016 Int. Conf. Netw. Inf. Syst. Comput., pp. 160-164, 2017, doi: 10.1109/icnisc.2016.043.

[6] L. C. Mota, E. D. Moreno, A. L. Ribeiro, and R. J. P. B. Salgueiro, "A comparative analysis of network management protocols in IoT applications," J. Comput. Sci., vol. 14, no. 9, pp. 1238-1246, 2018, doi: 10.3844/jcssp.2018.1238.1246.

[7] O. Marik and S. Zitta, "Comparative analysis of monitoring system for data networks," Int. Conf. Multimed. Comput. Syst. -Proceedings, pp. 563-568, 2014, doi: 10.1109/ICMCS.2014.6911307.

[8] L. Macura and M. Voznak, "Multi-Criteria Analysis and Prediction of Network Incidents Using Monitoring System," J. Adv. Eng. Comput., vol. 1, no. 1, p. 29, 2017 , doi: $10.25073 /$ jaec.201711.47.

[9] F. L. See, "Comparison of network monitoring systems," Wikipedia, Free Encycl., p. 1, 2019. [Online]. Available: https://en.wikipedia.org/wiki/Comparison_of_network_ monitoring_systems. [Accessed: 27-Dec-2019].

[10] C. M. Petruti, B. A. Puiu, I. A. Ivanciu, and V. Dobrota, "Automatic Management Solution in Cloud Using NtopNG and Zabbix," Proc. - 17th RoEduNet IEEE Int. Conf. Netw. Educ. Res. RoEduNet 2018, pp. 1-6, 2018, doi: 10.1109/ROEDUNET.2018.8514142.

[11] Nivedita and R. Kumar, "An improved Linux firewall using a hybrid frame of netfilter," Proc. - Int. Conf. Trends Electron. Informatics, ICEI 2017, vol. 2018Janua, pp. 657-662, 2018, doi: 


\subsection{9/ICOEI.2017.8300784.}

[12] J. Renita and N. E. Elizabeth, "Network's server monitoring and analysis using Nagios," Proc. 2017 Int. Conf. Wirel. Commun. Signal Process. Networking, WiSPNET 2017, vol. 2018-Janua, pp. 1904-1909, 2018, doi: 10.1109/WiSPNET.2017.8300092.

[13] P. Jain, Y. Munjal, J. Gera, and P. Gupta, "Performance Analysis of Various Server Hosting Techniques," Procedia Comput. Sci., vol. 173, no. C, pp. 70-77, 2020, doi: 10.1016/j.procs.2020.06.010.

[14] F. Rezac, J. Rozhon, M. Voznak, J. Slachta, and J. Safarik, "Multi-agent system for monitoring the quality of speech in computer networks," 2015 38th Int. Conf. Telecommun. Signal Process. TSP 2015, pp. 1-5, 2015, doi: 10.1109/TSP.2015.7296428.
[15] E. Ali, Susandri, and Rahmaddeni, "Optimizing Server Resource by Using Virtualization Technology," Procedia Comput. Sci., vol. 59, no. Iccsci, pp. 320-325, 2015, doi: 10.1016/j.procs.2015.07.572.

[16] H. J. Syed, A. Gani, R. W. Ahmad, M. K. Khan, and A. I. A. Ahmed, "Cloud monitoring: A review, taxonomy, and open research issues," J. Netw. Comput. Appl., vol. 98, no. September, pp. 11-26, 2017, doi: 10.1016/j.jnca.2017.08.021.

[17] S. Ullah, "Journal of Industrial Information Integration Design and implementation of an automated network monitoring and reporting back system," vol. 9, no. September 2017, pp. 24-34, 2018, doi: 10.1016/j.jii.2017.11.001. 